\title{
EL SUJETO DEL CONOCIMIENTO: BREVE ANÁLISIS EPISTEMOLÓGICO EN TORNO AL FENÓMENO DEL APRENDIZAJE
}

The subject of study: a brief epistemological analysis about the learning process

O sujeito do conhecimento: breve análise epistemológico em torno do fenômeno da aprendizagem

\author{
Sergio Manosalva Mena \\ Universidad Andrés Bello, Chile. Fono: +56 9 88081306. Correo electrónico: \\ smanosalvamena@gmail.com
}

\section{Resumen}

Con este artículo pretendo contribuir a una reflexión en torno a las teorías del aprendizaje de mayor uso en el campo de la pedagogía y psicología infantil; esto con la finalidad de tomar conciencia de que, bajo las teorías del aprendizaje, existen concepciones filosóficas con planteamientos claros respecto al ser humano como sujeto de conocimiento. Esto no es menor cuando estamos provocando que las instituciones educativas transformen sus actuales prácticas de administración escolar por una gestión educativa estratégica, donde el centro sea lo pedagógico desde una clara concepción filosófica respecto del sujeto epistémico.

Palabras clave: filosofía; aprendizaje; epistemología; infancia.

\begin{abstract}
I would like to contribute through this article to do some serious reflection on the most common learning theories in relation to pedagogy (education) and child psychology in order to become aware of some philosophical conceptions base don the Learning Theories that have a clear approach about the human being as the subject of study. This is not less when we are with the intention of producing an important change. This means that The Educational Institutions transform their current management practices into a strategic El sujeto del conocimiento: breve análisis epistemológico en torno al fenómeno del aprendizaje
\end{abstract}


education management where the center of the attention be teaching from a clear philosophical conception in relation to the epistemic subject.

Key words: philosophy; learning; epistemology; childhood.

\section{Resumo}

Com este artigo pretendo contribuir a uma reflexão em torno das teorias da aprendizagem de maior uso no campo da pedagogia e psicologia infantil; isto com a finalidade de tomar consciência de que, baixo as teorias da aprendizagem, existem concepções filosóficas com propostas claras com respeito ao ser humano como sujeito de conhecimento. Isto não é menor quando estamos a provocar que as instituições educativas transformem seus atuais práticas de administração escolar por um gerenciamento educativo estratégica, onde o centro seja o pedagógico desde uma clara concepção filosófica respeito do sujeito epistémico.

Palavras-chave: filosofía; aprendizagem; epistemología; infancia.

\section{Introducción}

Hablar del sujeto del conocimiento, necesariamente nos lleva a hablar de filosofía y luego muy en particular- de psicología, pues es esta última que ha manifestado un gran interés por el fenómeno del aprendizaje. Desde sus orígenes, la psicología está fuertemente vinculada con diferentes pensamientos filosóficos, de lo que resultan tres fases (Gondra, 2009) claramente delimitadas: pre psicología, psicología científica y eras de las escuelas psicológicas.

En la Grecia Antigua, el pensamiento helénico estuvo centrado en la teoría, el logos y el ser. Dentro de este pensamiento surgen los cuestionamientos por el alma, el conocimiento y la ética, pero no es sino de la mano de la biología (en específico de la fisiología) que la psicología se hace ciencia, con quien es considerado su padre al fundar la psicología experimental en Leipzig (Alemania) en el año 1879; me refiero a Wilhelm Wundt (1832-1920). A esta escuela estructuralista, se le sumaría la escuela funcionalista y la gestáltica.

El sujeto del conocimiento: breve análisis epistemológico en torno al fenómeno del aprendizaje 
Posteriormente entrarán en escena otras escuelas como la conductista, la psicoanalítica, la humanista, la cognitivista y la constructivista (Leahey, 1998). De igual modo, la psicología va abriendo nuevos horizontes y nuevos campos de acción que van complejizando una única forma de definirla; tal vez esto la emparenta aún mucho más con la filosofía desde donde fue concebida.

Estos nuevos campos de acción fueron perfilando ramas de la psicología claramente delimitadas (fisiológica, del desarrollo, infantil, clínica, comunitaria, organizacional, entre otras).

\section{Los orígenes de la psicología}

Si nos remontamos a los orígenes de la psicología, necesariamente debemos escudriñar en los primeros pensamientos en torno al logos - “el milagro griego", como ha sido señalado por algunos autores (Vernant, 2011: 116)- donde el mito fue desplazado por el logos, y con ello otras explicaciones de lo humano. De esta última, la filosofía se fue preocupando del universo espiritual, del alma y del cuerpo. Por ello podemos decir que los primeros pensamientos respecto de la naturaleza humana (ya no explicados desde la mitología), guardan relación con dos raíces teóricas antagónicas; así podemos hablar de una filosofía metafísica y una filosofía antropológica (Echeverría, 2007). Ambas, diferenciando un ideario político en cuanto a las concepciones de la naturaleza humana.

Las concepciones respecto del ser humano, del conocimiento y la pregunta por el conocer, fueron dando cuerpo en la antigua Grecia a la escuela de los escépticos con Pirrón de Elis (360 - 270 a C.) y la escuela de los dogmáticos con Zenón de Citio (333 - 264 a C.). Posteriormente dogmáticos como Pitágoras o Parménides, defensores de la aristocracia, influyen en el pensamiento de Sócrates, Platón y Aristóteles, quienes en la esencia de sus postulados son hermeneutas como el caso de Aristóteles (Ricoeur, 2008)- pero no constructivistas como lo son Protágoras (485-410 a C.) y Gorgias (483-375 a C.) que son defensores de una ontología antropológica y se encuentran influidos, el primero por Heráclito y el segundo por Jenófanes (570-478 a C.).

Al hacer un giro histórico relacionado con el surgimiento por el pensamiento en torno al ser humano, sus obras, arte y poesía, no podemos dejar de destacar el florecimiento El sujeto del conocimiento: breve análisis epistemológico en torno al fenómeno del aprendizaje 
de la cultura griega (Delius y Gatzemier, 2005), desde el siglo V a.C. hasta el siglo III a. C. (pues luego vendría su decadencia en el siglo II a. C. bajo el imperio romano). En esta época comienza una preocupación más allá de la naturaleza (physis) para centrarse en la polis y lo antropológico propiamente tal. Se destacan en la filosofía clásica de Atenas los que para muchos son considerados los representantes fundamentales de la filosofía de la Grecia Antigua. Entre ellos Sócrates, quien fue maestro de Platón y este, a su vez de Aristóteles, pero existen otros que, también ocupados por cuestiones de orden humanista hacen sendos aportes ontológicos bajo la herencia intelectual de una episteme antagónica que no será retomada sino muchos siglos después, con lo que se conoce como el giro lingüístico. De estos últimos destacan Protágoras y Gorgias, los llamados sofistas.

En Protágoras encontramos una sentencia que dice: "El hombre es la medida de todas las cosas. De las que existen, como existentes; de las que no existen, como no existentes" (cit. en López, 1997: 48). Esta es una postura muy similar a su antecesor Heráclito, quien sostiene taxativamente la variación de las cosas, los sujetos, las realidades. Dice: "Nadie se baña dos veces en el mismo río" (cit. en Figueroa, 1994: 33).

Por otra parte, Gorgias nos muestra todo su pensamiento y manera de razonar, escéptica y relativista en oposición a la verdad universal socrática. En él tenemos lo que sigue: "Nada existe, si algo existiera, no podría ser conocido; si pudiera ser conocido, no podría ser comunicado" (citado por Figueroa, 1994: 49).

Otros planteamientos de esta cercanía epistemológica en la interpretación de los fenómenos humanos, sociales y de la naturaleza, los podemos encontrar en Euclides y Arquímedes.

Llama la atención, pero no extraña, que todo el planteamiento teórico sustentado por los sofistas haya encontrado poco eco en la época, pero sabemos que gran parte de la fuerza de sus concepciones se vio debilitada por la desacreditación de que fueron objeto por parte de los dogmáticos. Como dice López (1997: 9) “(...) el pasado luminoso del nombre sofista queda sepultado bajo la montaña de autoridad socrática, platónica y aristotélica”.

De Aristóteles, quienes "heredan” sus argumentos y explicaciones son los empiropositivistas, quienes manifiestan que sólo se conoce lo que se puede ver (no reconocen otra El sujeto del conocimiento: breve análisis epistemológico en torno al fenómeno del aprendizaje 
realidad que no sean los hechos), y los sofistas, junto con el ideario platónico, encuentran eco en el racionalismo, específicamente en la figura de Descartes (1956-1650), quien sostiene que el ser humano sólo puede conocer aquello que construye.

Francis Bacon (1561-1626), considerado el fundador del empirismo, critica el silogismo como método para descubrir la verdad y plantea que el conocimiento se sustenta en la experiencia y el único método, por lo tanto, para develar la verdad es la inducción. Siendo esta corriente filosófica opuesta al racionalismo, se apoyará en las premisas que resultan del tipo de conocimiento propuesto por Newton e influirá en el planteamiento de John Locke (1623-1704), quien afirma que la mente es una tabula rasa en el que se escribe la experiencia, negando con esto la existencia de principios innatos en la mente (en Echeverría, 1991). Esta corriente de la filosofía será la precursora de las escuelas conductista y neoconductista de donde sus principales exponentes son Watson y Skinner.

Tanto Galileo (1564-1642) como Descartes resaltan al ser humano como constructor de sus propias teorías, por lo tanto, liberan al pensamiento del sometimiento a las cosas y a los acontecimientos. Con el experimento, Galileo se opone a las observaciones y descripciones de F. Bacon. Mas, no es sino con Newton que se diluye completamente el planteamiento aristotélico al publicar en 1687 su Principia, donde plantea los principios matemáticos de la filosofía natural. En Newton no hay un método de descubrimiento de una verdad que está fuera del entendimiento humano. El planteamiento de sus leyes causales y universales lo pone en oposición a la existencia de verdades innatas, constituyendo así las bases de legitimación del método científico, el cual es fuertemente criticado por Gadamer (1993) quien se resiste a la arrogancia de superioridad con que se muestra, cuando no es el mejor camino para la comprensión de la experiencia que sí se puede lograr a través del lenguaje.

Descartes tiene una gran influencia en la concepción de distintas escuelas de la psicología: en el estructuralismo de Wundt, en el funcionalismo de James y Dewey, en el psicoanálisis de Freud y Jung, y en el cognitivismo de Piaget y Bruner.

En un intento de explicación del conocimiento científico, Kant (1992) plantea que la ciencia es una actividad en la que participan ambas corrientes, tanto lo empírico como lo 
racional, pero no como una suma parcial de ambas posturas (a manera de la síntesis hegeliana), sino, en un acercamiento que se le reconoce como "idealismo". Pensamiento que queda expuesto en su "Crítica de la Razón Pura" (publicada originalmente en 1781). Su intento de conciliar la confrontación entre racionalistas y empiristas no representa, en un primer momento, una superación del dualismo filosófico (en sus dos formas de expresión del realismo), por ello enfoca al revés la cuestión del conocimiento preguntándose por el sujeto y no por el objeto de conocimiento. Con la filosofía crítica de Kant, podemos decir que se abre el mundo de una teoría de la comprensión. Es la influencia kantiana que podemos observar en los pensamientos de Schleiermacher, Wittgenstein, Habermas y Rawls (Ricoeur, 2002). Y en el campo especifico de la psicología, en el desarrollo de la escuela de la Gestalt de Wertheimer y Kofka, de la escuela humanista de Maslow y Rogers, y en la escuela constructivista de Vigotsky y Ausubel.

Así, junto con el Renacimiento también la Hermenéutica deja de ser la interpretación ingenua sostenida en el mito o la religión (como había sido concebida por una ola de pensadores - tal vez desde inicios de la humanidad-), para iniciar nuevos rumbos argumentándose en la ciencia. Pero este objetivismo epistemológico iniciado con la polarización cartesiana "sujeto-objeto", no permite a la Hermenéutica una comprensión de fenómenos humanos (de las Ciencias Humanas) pues ella se ocupa justamente del sujeto y su producción de significados en un contexto histórico específico. Por ello, la Hermenéutica se aleja de la concepción científica tradicional, para situarse en lo que podríamos distinguir como "doble hermenéutica" o interpretaciones para las comprensiones de comprensiones. Tal vez sea este ideario el que sitúa el nacimiento de la Hermenéutica a mediados del siglo XX (con sus raíces en Husserl y Nietzsche) y, aun cuando se señale como principales representantes de la Hermenéutica moderna a Heidegger, Gadamer, Vattimo y Ricoeur, podríamos situar el nacimiento de la Hermenéutica como disciplina concreta de la interpretación y comprensión lingüística, en los aportes de Friedrich Schleiermacher (17681834). Con él -quien es considerado un hermeneuta romántico- podemos decir que la Hermenéutica no tiene otro objeto que el lenguaje.

Es justamente Schleiermacher quien influyó fuertemente en el pensamiento y en la obra de Dilthey, así estamos en presencia de lo que podría ser una nueva escuela El sujeto del conocimiento: breve análisis epistemológico en torno al fenómeno del aprendizaje 
psicológica. Como nos señala Brío (2010) "la Psicología descriptiva y analítica, o Psicología comprensiva que Dilthey inaugura, tiene como objeto la vivencia como vida vivida" (p. 9).

Superada la concepción clásica del lenguaje (en lo que se ha considerado en llamar el giro lingüístico), la palabra es vista de forma inferencial y no como un código de representación; es decir, las palabras dicen más que las propias palabras. Como lo expresa Santander (2011) “(...) sabemos que el lenguaje no es transparente, los signos no son inocentes, que la connotación va con la denotación, que el lenguaje muestra, pero también distorsiona y oculta, que a veces lo expresado refleja directamente lo pensado y a veces sólo es un indicio ligero, sutil, cínico" (p. 208). El lenguaje produce sentidos por los sujetos $\mathrm{y}$, a la vez, los sujetos son producidos por y el lenguaje.

Es por las palabras que el sujeto deviene en subjetividad; es decir, el sujeto se constituye en sujeto ideológicamente al operar en el subconsciente la construcción básica de su identidad, en una suerte de estructura-funcionamiento en acoplamiento con el tono emocional básico definido en el postracionalismo de Guidano (1994). Las palabras entendidas y significadas se entrelazan con la emocionalidad para quedarse en el cuerpo que las materializa y las transforma en verbo de una manera tan transparente que no las podemos observar como condición de nuestra propia existencia. Luego, y sólo en la distancia de aquel o aquella que recibe la imposición ideológica que cargan nuestras palabras, podemos observar los sentidos que se opacan en nuestros discursos y, si hacemos un esfuerzo de doble hermenéutica, podemos tener la posibilidad de analizarlos.

\section{El nacimiento de las escuelas en psicología}

El legado platónico lo podemos situar en uno de los grandes de la filosofía con que se inicia la modernidad. Es Descartes un dualista que sitúa al ser humano en una composición almacuerpo, algo así como una máquina que es puesta en movimiento por el alma. Para él el alma es inextensa, libre e insustancial, en tanto el cuerpo es extenso, encerrado y material. Esta concepción lo sitúa en un teórico interaccionista al decir que alma y cuerpo interactúan mutuamente. En su empeño por llegar a la certidumbre de estas convicciones planteo su famoso "cogito ergo sum"; es decir, el pensamiento evidencia la existencia del alma, puesto

El sujeto del conocimiento: breve análisis epistemológico en torno al fenómeno del aprendizaje 
que del pensar no se puede dudar. Para él, de todo se puede dudar menos del pensamiento. En esta teoría interaccionista mente-cuerpo, no pudo dar respuestas a cómo el alma puede poner en movimiento el cuerpo, iniciando con ello nuevas interrogantes que retomarían más tarde Hume y Kant.

Por otra parte, un contemporáneo de Descartes, Tomas Hobbes (1588-1679), dio inicio al empirismo y sentó las bases del asociacionismo al plantear que la mente estaba compuesta sólo de experiencias sensibles. Posteriormente Jhon Locke (1632-1704) continuaría con los postulados de Hobbes, pero situándose en la experiencia y la razón como las condiciones necesarias para el conocimiento. Para Locke, las ideas tienen dos fuentes que las posibilitan; la primera, dice relación con las sensaciones y la segunda, con la reflexión, existiendo ideas simples e ideas complejas y sólo estas últimas se pueden analizar al descomponerlas en ideas simples (unidades de conocimiento).

El punto álgido del empirismo inglés lo podemos situar en Berkeley (1685-1753), Hume (1711-1776) y Hartley (1705-1757).

Berkeley (sucesor inmediato de Locke) "pensaba que la percepción era un acto de juicio basado en la experiencia" (Vargas, 2007: 20). Posteriormente Hume, sobre la base teórica de Locke, planteó una diferenciación entre impresiones e ideas. "Para Hume las sensaciones son impresiones más vigorosas y vivas que las ideas, que son relativamente más débiles y tenues" (Vargas, 2007: 21).

Continuando con la obra de los empiristas, quien funda la escuela del Asociacionismo, pero no la origina, es Alexander Bain (1818-1903). Con él el asociacionismo llegó a ser una subestructura de la Psicología Fisiológica, al convertirlo en sistema. Otro de sus grandes aportes a la psicología, fue fundar en 1876 la primera revista psicológica que tituló "Maind". Posteriormente, el asociacionismo alcanzó su punto máximo con James Mill (1773-1836) al postular que “(...) la Ley de la Asociación de ideas surge en base a la co-ocurrencia de sensaciones, por lo tanto, la asociación no es un poder, fuerza o causa; es simplemente una cuestión de contigüidad u ocurrencia" (Vargas, 2007: 22-23).

El sujeto del conocimiento: breve análisis epistemológico en torno al fenómeno del aprendizaje 
Mientras se va desarrollando lo que podemos llamar psicofisiología, hace su aparición Charles Darwin (1809-1862), quien hizo importantes contribuciones a la psicología. Dentro de ellas se destacan: "el concepto de evolución y su aplicación a los procesos psicológicos, la psicología comparada, el estudio de las emociones y su expresión, el estudio etológico del comportamiento humano, especialmente el infantil" (Vargas, 2007: 32). Su libro "El Origen de las Especies" (publicado en 1859), tuvo sendas repercusiones en la psicología de esos tiempos, pues junto con desafiar el Génesis, puso al ser humano en el reino animal.

Quien fuertemente se apoya en los planteamientos de Darwin, es el positivista inglés Herbert Spencer (1820-1903), autor de la teoría asociacionista-evolucionista y colaborador en el surgimiento de la Psicología Animal. Desde esta psicología comparada es que vimos surgir, desarrollarse y avanzar a la Psicología Objetiva. Sus máximos exponentes los podemos situar en la llamada Escuela Rusa, que se inició con Sechenov (1826-1905), y más tarde con Bechterev (1857-1927) y Pavlov (1849-1936).

Sechenov afirmó que "todo el pensamiento y la inteligencia dependen de la estimulación para existir y que todos los actos de la vida consciente o inconsciente son reflejos" (Vargas, 2007: 35). Pavlov, al leer los trabajos de Sechenov, quedó influenciado por sus planteamientos y replanteó sus estudios fisiológicos sobre las secreciones gástricas. "Fue así como descubrió que los jugos digestivos empiezan a fluir copiosamente, cuando el sujeto animal anticipa la comida y a partir de esta observación, desarrolló la técnica de los 'reflejos condicionados' "(Vargas, 2007: 36). Aunque Pavlov no se consideró a sí mismo como un psicólogo, hizo grandes aportes a lo que distinguiríamos posteriormente como Escuela Conductista, pues su teoría del Condicionamiento Clásico abrió la posibilidad de que Watson desarrollara su teoría estimulo-respuesta.

Por su parte, Bechterev también investigó sobre los reflejos condicionados, pero su afán estaba puesto en las respuestas motoras y no salivales. Ello lo llevó a estudiar en sujetos humanos y animales. Tal vez su interés por la psiquiatría lo alejó de la psicología, siendo poco conocido en este campo de estudio, y su oposición a Wundt le valió varios 
opositores que defendían la introspección como método para estudiar los fenómenos psicológicos.

Otro de los que se apoya en los planteamientos de Darwin es William James (18421910) quien funda, a fines del siglo XIX, lo que se conoce como escuela funcionalista en oposición a la escuela estructuralista. James extrapola los planteamientos de Darwin señalando que se conservan las características que tienen beneficios y se pierden las que no son útiles para la viabilidad del sujeto con su entorno. Su interés estaba puesto en las funciones de la consciencia.

En oposición al reduccionismo positivista y al surgimiento de un interés por la naturaleza de la experiencia consciente, Wertheimer funda y lidera, a principios del siglo $\mathrm{XX}$, un grupo de investigadores ocupados por la totalidad de la consciencia humana en clara disidencia con el estructuralismo. Esta escuela plantea que la totalidad es mayor que la suma de sus partes. Surge así lo que se conoce como la escuela de la Gestalt.

Con estas tres escuelas (estructuralista, funcionalista, gestáltica) podemos decir que la psicología sienta sus bases teóricas propiamente tal.

\section{Psicologías contemporáneas (o psicologías del siglo XX)}

Son variadas y muchas las teorías que tratan de explicar el conocimiento en el ser humano y, en específico, su capacidad de aprendizaje y los procesos implicados en este fenómeno, por ello sólo me referiré a dos grandes corrientes de gran influencia en el campo educativo. Sé que hay un sesgo bastante grande en esta elección, pero mi pretensión es sólo mostrar algunas tensiones teóricas que no acaban con explicar al sujeto cognoscente y su capacidad de aprendizaje. Así, y con todo, debemos considerar estas corrientes pues están presentes (querámoslo o no) en toda organización humana, y en específico en los sistemas de educación formal. Por ello, si deseamos una transformación o un cambio innovador de los sistemas educativos, debemos conocer (aunque sea en parte), sus proposiciones explicativas que demandarán un tipo particular de gestión escolar. Las corrientes escogidas son el conductismo y el constructivismo.

El sujeto del conocimiento: breve análisis epistemológico en torno al fenómeno del aprendizaje 
Conductismo. Con Watson (1878-1958), la Psicología Objetiva se convirtió en Conductismo al publicar en 1913 un artículo titulado "La Psicología como un Conductista la ve".

Es celebre su frase "Denme al bebé y lo haré gatear y caminar, en el mundo al que lo traigo, lo haré escalar y usar sus manos en la construcción de edificios de piedra o madera; lo haré un ladrón, un pistolero o un adicto a las drogas. La posibilidad de formarlo en cualquier dirección es casi ilimitada" (cit. en Matson, 1984: 26). Tal vez esta sentencia sitúe al conductismo como una ciencia que no respeta su objeto de estudio, pues hace del otro una cosificación, alguien a quien controlar y manipular, empero muchos investigadores afirman que todos los psicólogos actuales son conductistas (Vargas, 2007).

Gran influencia tuvo Pavlov y Watson en los planteamientos teóricos de Skinner (1904-1990), quien realiza una distinción entre dos tipos de conducta; dice que existen las conductas 'respondientes' y las ‘operantes'; se refirió a las primeras como las conductas que se observan en respuesta a la presentación de un estímulo, y las operantes al tipo de conductas que operan sobre el medio o entorno posibilitando un cambio.

Si bien hoy en día se cuestiona y critica constantemente el uso del Conductismo, se puede descubrir un nuevo aspecto en el Condicionamiento Operante de Skinner.

Este nuevo aspecto en realidad no es nuevo, sino que se ha mantenido cubierto por la mala fama que el Conductismo ha generado desde hace mucho tiempo, siendo "satanizado", es decir, mirado como sinónimo de la crueldad misma, tergiversando se verdadera utilidad en todo proceso educativo.

Para Skinner (Boeree, 1998: 2), "un comportamiento seguido de un estímulo reforzador provoca una probabilidad incrementada de ese comportamiento en el futuro". He aquí que identificamos entonces la primera y más innata herramienta del Condicionamiento Operante, el Estímulo Reforzador.

Este Estímulo Reforzador, a su vez se divide en dos, por un lado, está el Refuerzo Positivo que "se da cuando el refuerzo es un estímulo que aumenta la probabilidad de la emisión de la conducta que provoca la aparición del refuerzo" (Boeree, 1998: 2), y en el 
otro lado está el Refuerzo Negativo que "se da cuando la conducta tiene como consecuencia la desaparición de un estímulo aversivo. Como en el caso del refuerzo positivo, en el sujeto se produce un incremento de la probabilidad de que una conducta se realice" (Boeree, 1998: 3).

Además de estos elementos, existe un recurso que también se asocia al Condicionamiento Operante, y es el Castigo, que, sin embargo, Skinner no apoyaba. El Castigo tiene como propósito disminuir una conducta indeseada a través de un estímulo aversivo. Del mismo modo que el Estímulo Reforzador contiene dos elementos operacionales sobre las conductas, el Castigo también se puede aplicar de dos formas: por Omisión (privar de algo), o por Aplicación (aplicación de una acción aversiva).

Teniendo ya más claro el panorama en cuanto a los conceptos, me dedicaré a este pequeño análisis reflexivo sobre el aspecto "oculto" del Condicionamiento Operante que viene intrínseco en nosotros y se da en nuestras formas de relacionarnos.

De acuerdo a la primera definición de Condicionamiento Operante expuesta anteriormente, como primer punto, puedo descubrir y analizar que quien tiene el dominio de sus acciones o respuestas, luego de ser "educado" (o "manipulado", para los más críticos) por otra persona, es el propio organismo, es decir, el propio sujeto, que buscará salir victorioso de la prueba impuesta por el otro.

Y como segundo punto, que resulta ser el evaluado, rescatado y avalado por muchos teóricos, es el hecho que, dentro de la operacionalidad de este mecanismo o metodología, se producen aprendizajes efectivos, además de desarrollar o estimular la capacidad asociativa, de resolución de problemas y de crear nuevas estrategias para conseguir lo deseado.

Concuerdo con Kurtz que "mientras aun permanezca un núcleo humanista fundamental en la ciencia conductista, debemos distinguir entre el conductismo como un modo científico de explicación y el conductismo como una tecnología de control" (cit. en Matson, 1984: 69).

El constructivismo. En esta corriente podemos situar a Lev Vigotsky (1896-1934), Jean Piaget (1896-1980), Jerome Bruner (1915-) David Ausubel (1918-) y Howard Gardner 
(1943-), entre otros, pero básicamente se les asocia a dos grandes estudios del desarrollo humano: Piaget y Vigotsky. Ambos plantean que la psicología debe preocuparse del estudio de los procesos mentales superiores. Aquellos procesos que son propiamente humanos. Como es en los niños donde mejor se pueden observar los procesos, sus estudios se focalizan en este grupo etario.

Participando ambos de la idea que es el ser humano el que construye sus propias estructuras cognitivas, se dan algunas diferencias que son más bien complementarias que antagónicas.

Piaget postula que el desarrollo cognitivo del sujeto se da en base a la construcción de sus propias estructuras cognitivas. Esta la explica a través de la dinámica de la asimilación y acomodación, siendo la asimilación el proceso primario y la acomodación el proceso secundario.

El desarrollo en Piaget es un esfuerzo por lograr el equilibrio entre dos conjuntos de principios que operan en el presente: asimilación del mundo al pensamiento representativo tal y como se ha desarrollado en este momento, y acomodación al mundo por medio de cambios en el pensamiento que lo representan mejor (Bruner, 1986). En Piaget, primero está la estructura y luego la experiencia.

Mientras Piaget supone el proceso de desarrollo como un proceso espontáneo, Vigotsky plantea que la construcción de las estructuras cognitivas es el resultado de la presión ejercida por la educación. Es decir, que el desarrollo del ser humano es un proceso provocado por la educación.

Para Vigotsky sin educación no hay desarrollo humano. Para Piaget la educación se limita a facilitar este desarrollo. En este sentido, para Piaget el educador es un "facilitador", mientras que para Vigotsky es un "provocador".

Actualmente uno de los psicólogos de gran influencia en el currículum escolar es Jerome Bruner. Este psicólogo norteamericano, influenciado en sus primeros trabajos fuertemente por las orientaciones de Piaget (década del '60), va internalizando 
gradualmente la postura de vogotskiana (década del '80), desde donde hace aportes significativos de gran impacto en el proceso educativo y su práctica.

Desde su óptica, considera a tres grandes de la psicología en estudios de la infancia: Freud, Piaget y Vigotsky. A Freud lo ve más preocupado por el pasado, a Piaget por el presente y a Vigotsky por el futuro (Bruner, 1986).

Específicamente en el campo de la educación, J. Bruner plantea unos principios ya desarrollados por Ausubel en 1968, estos son el principio de la significatividad y de la funcionalidad en los aprendizajes de los conocimientos seleccionados de la cultura. Cuando se dice que el aprendizaje debe ser significativo se está haciendo referencia a que el nuevo material de aprendizaje sea asimilado a la estructura cognoscitiva del educador, es decir, a lo que él ya sabe. Es mediante este proceso que el alumno va construyendo su realidad.

Para que el aprendizaje sea significativo deben darse dos condiciones: la primera es que el contenido debe ser potencialmente significativo para el alumno, tanto en su estructura interna como en su posibilidad de asimilación; la segunda es que debe existir por parte del alumno una actitud favorable para aprender significativamente. Si no se dan estas dos condiciones es fácil caer en un tipo de aprendizaje repetitivo que al no modificar los esquemas cognitivos no le serán funcionales y, por lo tanto, se olvidarán fácilmente. El que los conocimientos aprendidos sean funcionales, es decir, que puedan ser reutilizados cuando las circunstancias así lo exijan, debe ser una permanente preocupación del sistema educativo, como así mismo considerar que el alumno es activo no sólo cuando descubre o inventa por sí mismo, sino también cuando atribuye un significado y una funcionalidad a lo que se le enseña. La manipulación y el descubrimiento, es sólo una de las vías en el logro de aprendizajes significativos.

Aquí se hace necesario diferenciar entre lo que al alumno puede hacer por sí solo y lo que es capaz de realizar con la participación de otra persona. Lo que Vigotsky ha llamado "zona de desarrollo próximo"; es decir, la zona que se sitúa entre el nivel del desarrollo efectivo y el nivel de desarrollo potencial del alumno.

De acuerdo con este autor, uno de los errores más frecuentes que se comete en educación es prestar sólo atención al nivel de desarrollo actual, efectivo, que el menor El sujeto del conocimiento: breve análisis epistemológico en torno al fenómeno del aprendizaje 
presenta y no al nivel del desarrollo potencial que puede alcanzar. Es aquí donde radica según él- una buena enseñanza. "La única buena enseñanza es la que se adelanta al desarrollo" (Vigotsky, 1977). Esto tiene fuertes implicaciones educativas, pues sitúa al educador ya no como un mero facilitador de aprendizaje, sino fundamentalmente como un provocador de aprendizaje.

Así, la educación institucional formal debe comenzar desde el nivel de desarrollo efectivo del educando para, desde ahí, hacerlo progresar a nuevas zonas de desarrollo, a través de un proceso de aprendizaje donde el estudiante es el que construye, enriquece, modifica, diversifica y coordina sus esquemas de conocimientos (Coll, 1987). Esta actividad constructiva no es individual, sino que es parte de una actividad interpersonal, una interactividad entre profesor y alumno, pero también entre alumno y alumno.

Como lo señala Coll (1987), lo que determina el futuro intelectual de un niño no son los estímulos que lo rodean, sino el papel mediador de los adultos, es decir, las actividades en las que el adulto y niño se embarcan en una actividad paralela alrededor de un objeto, a propósito del él. Ahí en esa escena en la que el adulto y el niño se enfrascan en una actividad conjunta, en la que el lenguaje actúa como soldadura entre la vida mental del adulto y la del niño, es donde parece que radica, en buena medida, la esencia de la estimulación cognitiva de los niños pequeños y de los que no lo son tanto.

Estas concepciones del aprendizaje conllevan importantes implicaciones en las diversas áreas del desarrollo humano y en cómo se debe concebir el acto educativo, pues en estas teorías el estudiante deviene en sujeto de construcción de conocimiento, lo que los aleja radicalmente de las concepciones del sujeto como objeto de conocimiento implícitas en el conductismo.

La verdadera educación es un acto amoroso de relaciones humanas.

\section{Conclusiones}

Dada la hipercomplejidad que la psicología conlleva, necesariamente debe abrirse a otros campos disciplinarios que converjan sus aportes para una comprensión, análisis e intervención sistémica y del comportamiento individual de toda organización como sistema

El sujeto del conocimiento: breve análisis epistemológico en torno al fenómeno del aprendizaje 
social (sistema vivo), esto implica el desafío de adquirir ciertos conocimientos del devenir económico, político y cultural que tienen incidencias en la viabilidad de todo individuo y de toda organización. Como nos señala Rodríguez (2004) “(...) observamos que el propio concepto de organización puede variar en función de la unidad de análisis que se utilice, concibiéndola como un conjunto de individuos, de grupos o bien como un sistema de individuos y de grupos interrelacionados, circunstancia que produce profundas diferencias en el modo de conocimiento de esta realidad social y, por lo tanto, en las líneas de investigación y de intervención propuestas" (p. 34), por ello no es trivial ahondar en el fenómeno del aprendizaje desde las ontologías explicativas del sujeto cognoscente según las perspectivas paradigmáticas de las corrientes filosóficas que las sustentan. Ya no es posible recurrir a la fragmentación humana o a reduccionismos disciplinarios o racionalidades cuantitativas en las explicaciones respecto del sujeto epistémico y los fenómenos de aprendizajes. Se hace altamente necesario levantar nuevas teorías sobre lo humano, sus dimensiones humanas y sus potenciaciones cognitivas desde el paradigma de la complejidad, esto necesariamente conlleva el situarnos como observadores hermenéuticos críticos y sistémicos, con capacidad de desarrollar pensamiento rizomàtico, en concordancia con ver al otro como un sujeto coexistencial, holístico, integral y hologramàtico. Ciertamente esta no es una tarea fácil, pues somos herederos de una metafísica trascendental, pero no por ello debemos dejar de orientarnos a la transformación. Como nos lo dice Silvio Rodríguez “...lo más terrible se aprende enseguida y lo hermoso nos cuesta la vida".

\section{Referencias bibliográficas}

Boeree, G. (1998). Teorías de la personalidad: Hans Eysenck. Obtenido de Teorías de la personalidad: Recuperado de

http://www.psicologiaonline.com/ebooks/personalidad/eysenck.htm

Boeree, G. y Goutier, R. (2005) Teorías de la personalidad. República Dominicana: UNIBE.

Brío, Ma. C. (2010) Psicofarmacología y neurociencias. B. Aires: Ed. Siens.

El sujeto del conocimiento: breve análisis epistemológico en torno al fenómeno del aprendizaje 
Canguilhem, G. (2001) ¿Qué es la psicología?. Argentina: Ed. El Seminario.

Cruz, L. (2012) Reseña y aportes de la Hermenéutica: miradas desde el constructivismo. Revista de Psicología. Vol 21. $\mathrm{N}^{\circ}$ 1, Junio. En: http://www.revistapsicologia.uchile.cl/index.php/RDP/article/viewFile/19983/21137 (Recuperado en abril de 2013).

Coll, C. (1987) Psicología y Curriculum. Barcelona: Laila.

Echeverría, R. (1988) El Búho de Minerva. Santiago de Chile: PIIE

Echeverría, R. (2007) Raíces de sentido. Santiago de Chile: J C Sáez editor.

Echeverría, R. (2007) Por la senda del pensar ontológico. Santiago de Chile: J C Sáez editor.

Foucault, M. (2002) La Hermenéutica del Sujeto. México. Fondo de la Cultura Económica. (2da edición).

Gadamer, H. (1993) Verdad y Método. Salamanca: Sígueme.

Guidano, V. (1987) La Complejidad del Sí Mismo. New York: The Guilford Press.

Gondra, J. (2009) Historia de la psicología, Introducción al pensamiento moderno. Madrid: Editorial Síntesis.

Hegel, G. (1971) Fenomenología del Espíritu. México: F.C.E.

Kant, I. (1992) Crítica de la Razón Pura. Tomo I y II. Buenos Aires: Losada. (13ª edición).

Lahey, B. (1999) Introducción a la psicología. España: McGraw-Hill.

López, R. (1997) Maestros Innovadores. Educación, Política y Persuasión en los Sofistas. Santiago de Chile: Bravo y Allende Editores.

Matson, F. (1984) Conductismo y humanismo. México: Trillas.

Maturana, H. (1992) Emociones y lenguaje en educación y política. Santiago de Chile: Hachette.

Maturana, H. (1996) La Realidad: ¿Objetiva o construida? II Fundamentos biológicos del conocimiento. México: Anthropos.

El sujeto del conocimiento: breve análisis epistemológico en torno al fenómeno del aprendizaje 
Maturana, H. (1999) Transformación en la convivencia. Santiago de Chile: Dolmen ediciones.

Ricoeur, P. (2002) Del Texto a la Acción. México: FCE.

Ricoeur, P. (2006) Sí Mismo como Otro. México. Siglo Veintiuno. (3ra edición).

Ricoeur, P. (2008) El conflicto de las interpretaciones. Ensayos sobre hermenéutica. México: FCE.

Rorty, R. (1990) El Giro Lingüístico. España: Paidós.

Santander, P. (2011) Por qué y cómo hacer análisis de discurso. Cinta de Moebio 41. En: www.moebio.uchile.cl/41/santander.html (Recuperado en marzo de 2013).

Vargas, J. (2007) El conductismo en la historia de la psicología. México: Asociación Oaxaqueña de psicología A.C.

Vernant, J. (1992) Los orígenes del pensamiento griego. Barcelona: Paidós.

Wittgenstein, L. (1991) Sobre la Certeza. Barcelona: Gedisa.

El sujeto del conocimiento: breve análisis epistemológico en torno al fenómeno del aprendizaje 